\title{
Penetrance of the p53 Gene in Uterine Fibroids in Senegalese Women
}

\author{
Ndime Fama ${ }^{1,}$, , Tendeng Jacques Noël ${ }^{2}$, Kénémé Bineta ${ }^{1}$, Sembène Mbacké $^{1,3}$ \\ ${ }^{1}$ Department of Animal Biology, Faculty of Science and Technology, University Cheikh Anta Diop of Dakar, Dakar, Senegal \\ ${ }^{2}$ Service of General Surgery, Regional Hospital Center of Saint-Louis, University Gaston Berger of Saint-louis, Saint-Louis, Senegal \\ ${ }^{3}$ Department of Animal Biology, Faculty of Science and Technology, University Cheikh Anta Diop of Dakar, Biology Center for Population \\ Management (GENGESPOP), Institute of Research and Development, IRD/Bel-Air, Dakar, Sénégal
}

\section{Email address:}

fama.ndime@ucad.edu.sn (N. Fama), jacques-noel.tendeng@ugb.edu.sn(T. J. Noël), bineta.keneme@ucad.edu.sn(K. Bineta), mbacke.sembene@ucad.edu.sn(S. Mbacké)

*Corresponding author

\section{To cite this article:}

Ndime Fama, Tendeng Jacques Noël, Kénémé Bineta, Sembène Mbacké. Penetrance of the p53 Gene in Uterine Fibroids in Senegalese Women. International Journal of Genetics and Genomics. Vol. 8, No. 3, 2020, pp. 106-113. doi: 10.11648/j.ijgg.20200803.13

Received: July 8, 2020; Accepted: July 25, 2020; Published: September 24, 2020

\begin{abstract}
Uterine Leiomyoma are a very common benign tumors, affecting $20-30 \%$ of the female population over 35 years of age. Black women are the most affected compared to Caucasian women. In order to determine the genetic mecanisms involved in uterine fibroids in senegalese women, the study of penetrance of mutations of exon 4 of the gene was carried out. Our study is based on 27 patients with uterine fibroids. Samples of tumour tissue and blood were taken from each patient. After PCR-Sequencing, identification of mutations was carried out using Mutation Surveyor 5.0.1 and AlamutVisual 2.12 software. Pathogenicity mutations was evaluated with Polyphen-2, Mutation Taster and SIFT. After cleaning, correcting and aligning of sequences with BioEdit software, nucleotide variability, diversity, genetic evolution, correlation of tumors with epidemiological factors and tumors prevalence were determined with Dnasp 5.10.01, MEGA 7.0.14, Arlequin 3.5.3.1 and Rstudio 3.5.1 statistical software. Our results showed a high rate of polymorphism in tumour tissues (19 mutations) compared to blood samples ( 1 single mutation) but also a genetic difference between tumour and blood tissues. Mutations c. $164 \mathrm{C}>\mathrm{A}$ and c. $215 \mathrm{C}>\mathrm{G}$ affecting respectively codon 55 and 72 of $p 53$ gene were significantly present in uterine fibroids tissues compared to blood. A first time mutation at position c.326T $>$ C located in a specific DNA binding domain (a highly conserved area) and having pathological effects was found in uterine myomas. They also showed a structuring of the leiomyomas according to the age of the patient (30-40 years are the most affected). In conclusion, this is a fist study in Senegal associating the polymorphism of the $p 53$ gene and the occurrence of uterine fibroids showing that some of variants found in tumour tissues could constitute a susceptibility factor in Senegalese women.
\end{abstract}

Keywords: Uterine Fibroids, p53, Senegal

\section{Introduction}

Leiomyomas or fibromyomas, commonly called uterine fibroids, are the most common smooth muscle tumours of the female reproductive tract [1] They are also the most common benign tumours in women of reproductive age and the main indication for hysterectomy (removal of the uterus) in premenopausal women [2].

Black women (American and African) have a greater burden with a higher incidence, showing the most severe symptoms with larger tumours, giving them a higher risk of hysterectomy (three times higher) compared to white women [3].

In Senegal, according to studies carried out by [4], uterine fibroids represent $58.82 \%$ of gynecological disorders operated on at the DANTEC surgical clinic in Dakar, be a total of $15 \%$ of all surgical pathology.

Although the exact cause(s) of uterine fibroids remains unknown, risk factors well identified by various epidemiological studies have been established such as age at menarche and exposure to hormones (progesterone and 
estrogens) but also other factors have been identified as protective such as smoking, use of oral contraceptives and multiparity [5].

However, with the advent of molecular biology, many arguments suggest that genetic factors play a decisive role. Genetic study is oriented towards the search for genes predisposing to the occurrence of myomas and a cytogenetic modification of the cell clone of a myoma promoting its growth and possibly its malignant degeneration.

In view of the importance of genetic modifications in human neoplasms and the role of the $p 53$ gene in the repair of DNA mismatches and in the apoptosis process, we have set ourselves the objective of contributing to the evaluation of the prevalence of mutations of exon 4 of the p53 gene identified in cases of uterine fibroids in order to identify those that could be determinant in the appearance of these myomas in Senegal.

\section{Materials and Methods}

\subsection{Samples Collection}

Tissue samples obtained following surgery (27 tumour tissues) and peripheral blood samples (10 controls) were recruited from the Military Hospital of Ouakam and General Hospital Idrissa Pouye. After informed consent Clinical and pathological data were recorded including age, ethnicity, age, BMI, parity and gestity.

Table 1. Characteristics of epidemiological parameters.

\begin{tabular}{lll}
\hline $\begin{array}{l}\text { Epidemiological } \\
\text { parameters }\end{array}$ & Groups & $\begin{array}{l}\text { Number of patients } \\
(\%)\end{array}$ \\
\hline \multirow{2}{*}{ Age $(\mathrm{n}=18)$} & $\leq 30$ & $2(11.11 \%)$ \\
& {$[30-40]$} & $10(55.55 \%)$ \\
Gestity $(\mathrm{n}=13)$ & $\geq 40$ & $6(33.33 \%)$ \\
& 1 & $9(69.23 \%)$ \\
BMI $(\mathrm{n}=7)$ & {$[1-3]$} & $4(30.77 \%)$ \\
& $\leq 24$ & $4(57.14 \%)$ \\
& {$[24-29]$} & $3(42.85 \%)$ \\
Ethnic group $(\mathrm{n}=12)$ & Wolof & $6(50 \%)$ \\
& Toucouleur & $2(16.66 \%)$ \\
& Peulh & $2(16.66 \%)$ \\
Parity $(\mathrm{n}=13)$ & Lebou & $1(8.33 \%)$ \\
& 0 & $1(8.33 \%)$ \\
& 1 & $10(76.92 \%)$ \\
\hline
\end{tabular}

\subsection{DNA Extraction and Sequencing}

Total DNA of each sample was extracted using the Qiagen DNeasy Tissues and Blood kit. For polymerase chain reaction, the primers (5'TCC CCC TTG CCG TCC CAA3') and (5'CGT GCA AGT CAC AGA CTT3') framing the polymorphism of codon 72 located at exon 4 (12021 to 12299 ) were used to amplify a 279 bp region of the $p 53$ gene [6]. The quality of the PCR products was evaluated by electrophoretic migration with a $1.5 \%$ agarose gel. Sequencing reactions were carried out in an MJ Research PTC-224 Peltier thermal cycler with ABIPRISM BigDye TM Terminator Cycle kits. Each sample was sequenced using forward primer.

\subsection{Molecular Analysis}

Detection of mutations

To determine the mutations and their positions relative to the P53 gene, the raw sequencing data were submitted to the Mutation Surveyor software version 5.0.1 (www.softgenetics.com). This is done by comparing the chromatogram of each sequence with the reference sequence incorporated in the software in question and also with the one found in the Genbank database under the accession number NT 0107187571220.

Prediction of the pathogenicity of mutations

The mutations detected are then submitted to the MutationTaster, SIFT and Polyphen 2 databases, which are software programs that assist in the interpretation of genetic mutations identified in the human genome. These software programs use scores to predict whether or not amino acid substitution has an effect on the protein produced.

Genetic diversity

After correction, the sequences were submitted to BioEdit software version 8.0.0[7] for multiple alignment using the ClustalW algorithm. The obtained sequences were thoroughly checked, cleaned and aligned to determine site homologies among other things, but also to be able to perform other genetic analyses, including the determination of genetic variability, diversity and differentiation indexes, as well as the frequency of each mutation. The basic parameters of genetic diversity including: the number of polymorphic sites, the total number of mutations (Eta), the total number of haplotypes (ha), the nature of the mutations ( $\%$ transitions and $\%$ transversions) and the $\mathrm{Z}$ test selection were obtained using MEGA software version 7.0.14[8] and DnaSP version 5.10.01[9]. The comparison of amino acids between controls and uterine myoma tissue was obtained using MEGA version 7.0 software [8]. As the $p 53$ gene is a coding gene, amino acid frequency will first be done by transforming the nucleotide sequences into protein sequences by choosing the best reading frame. To see if there is a difference in the frequency distribution of each amino acid between blood and tumour tissue, the database was submitted to $\mathrm{R}$ version 3.3.1 software [18]. Shapiro Wilk's normality test was performed to see if the data follows a normal distribution. In the case of a normal distribution, the Student's t-test is performed for the comparison of averages; otherwise the Wilcoxon test is used. The confidence interval is fixed at $5 \%$.

The genetic differentiation factor (Fst) between pairs of populations was estimated with Arlequin software version 3.5.1.3 [10] to assess the degree of genetic differentiation between tumour tissues and controls. Arlequin software version 3.5.1.3 [10] was also used to estimate genetic variation according to epidemiological parameters (gestity (number of pregnancies), parity (number of children per woman), patient age, ethnicity and $\mathrm{BMI}=$ Body Mass Index) in order to see which risk factors are involved in this pathology in Senegal. The Tajima D, $\mathrm{F}^{*}$ and $\mathrm{D}^{*}$ of $\mathrm{Fu}$ and $\mathrm{Li}$ tests (based on the number of singletons sites) to determine the type of populations we have as well as the graphical 
representation (mistmatch distribution) of the distribution of genetic distances existing between tumour tissues taken in pairs have been released with Arlequin 3.5.1.3 [9], [10]. The mismatch distribution curve under the assumption of a growing population was drawn with the Excel spreadsheet. The demographic indexes SSD (Sum of Squared Deviation) and Rag (Raggedness Index of Harpending) were obtained with the Arlequin 3.5.1.3 software [10] to validate the expansion model.

\section{Results}

\subsection{Nature and Position of Mutations}

Comparison of the chromatograms with the one incorporated in the Genbank database (NT_010718_7571220) revealed variability in p53 in both tumour and blood tissues except for two samples. None of the mutations found were common to both tissues. The results indicate numerous variations in exon 4 of the p53 gene of which 2 variations have been listed in the AlamutVisual database version $2.12($ c. $215 \mathrm{C}>\mathrm{G}$, c. $326 \mathrm{~T}>\mathrm{C})$ but also other variations (5) that can be considered as new (c. $275 \mathrm{C}>\mathrm{G}, \quad$ c. $215 \_216 \mathrm{insG}, \quad$ c. $164 \mathrm{C}>\mathrm{A}, \quad$ c.274 275insG, c.306C $>$ A). They are mostly heterozygous mutations or base insertions leading most often to a change of amino acids.

Table 2. List of mutations on exon 4 of gene P53.

\begin{tabular}{lll}
\hline Position mutation & Codon assigned & DbSNP \\
\hline UTERINE FIBROIDS ( $\mathrm{n}=27)$ & & \\
$\begin{array}{l}\text { c. } 164 \mathrm{C}>\mathrm{A} \\
\text { Het c.215 C }>\mathrm{G}\end{array}$ & Thr55Asn & \\
c. 215 216insG & Pro72Arg & rs1042522 \\
c. $274-275 \mathrm{InsG}$ & Val73Argfs*76 & \\
Het c.326 T $>\mathrm{C}$ (deleterious mutation) & Pro92Argfs*57 & \\
Het c.306 C $>$ A & Thr109Ser & rs1064796722 \\
BLOOD $(\mathrm{n}=10)$ & & \\
Het c. $275 \mathrm{C}>\mathrm{G}$ & Pro92Arg & \\
\hline
\end{tabular}
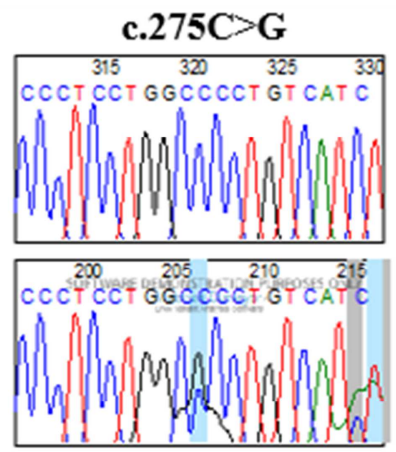

c. 274275 insG

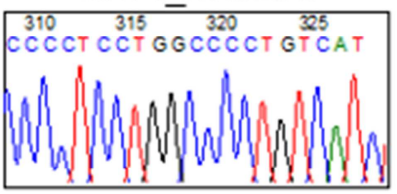

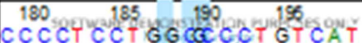

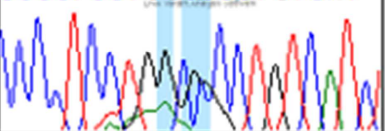

c. 215216 insG
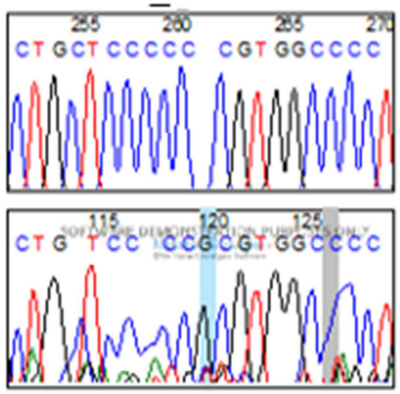
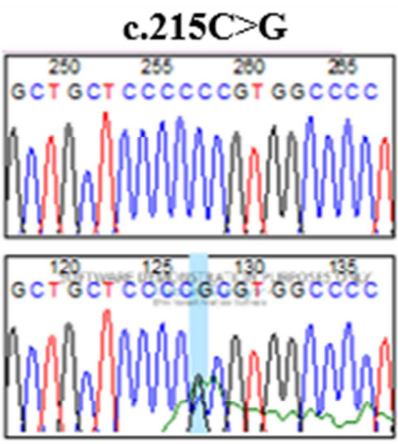

c. $306 \mathrm{C}>\mathrm{A}$
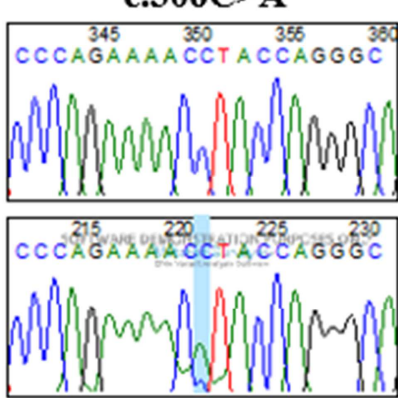
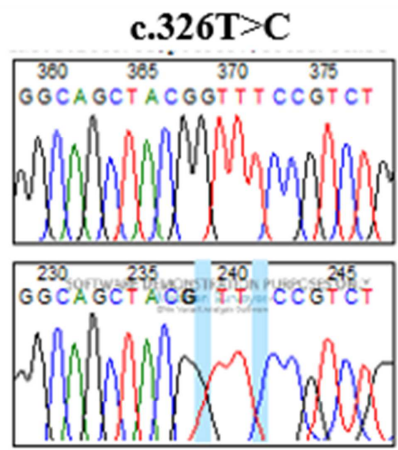

c. $164 \mathrm{C}>\mathrm{A}$
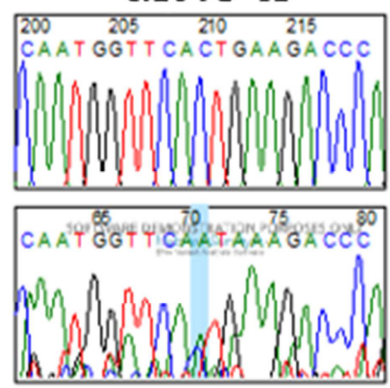

Figure 1. Heterozygous SNP of the exon 4 of p53 gene.

We detected 13 mutations, most of which are considered to be a neutral polymorphism and should be benign except for mutation at c.326T $>\mathrm{C}$ considered to be probably pathogenic by the three mutation prediction applications
(MutationTaster, SIFT and Polyphen-2). The following mutations have been found in the literature c. $215 \mathrm{C}>\mathrm{G}$ (rs1042522) and c.326T $>$ C (rs rs1064796722) associated with certain types of pathologies. 
Table 3. Nature of mutations.

\begin{tabular}{|c|c|c|c|c|c|}
\hline Mutations & Amino acids & Effect on coding & MutationTaster & SIFT (score) & Polyphen-2 (score) \\
\hline c.P98C $>\mathrm{T}$ & p. (Ser33Phe) & Non-Synonymous & Polymorphism & tolerated $(0.23)$ & Benign $(0.005)$ \\
\hline c. $112 \mathrm{C}>\mathrm{A}$ & p. (Gln38Lys) & Non-Synonymous & Polymorphism & tolerated $(0.94)$ & Benign (0.01) \\
\hline c. $134 \mathrm{~T}>\mathrm{A}$ & p. (Leu45Gln) & Non-Synonymous & Polymorphism & tolerated $(0.07)$ & Benign (0.245) \\
\hline c. $137 \mathrm{C}>\mathrm{A}$ & p. (Ser46Tyr) & Non-Synonymous & Polymorphism & Deleterious $(0)$ & Benign (0.09) \\
\hline c. $150 \mathrm{~T}>\mathrm{G}$ & p. (Ile50Met) & Non-Synonymous & Polymorphism & tolerated $(0.3)$ & Benign (0.187) \\
\hline c. $164 \mathrm{C}>\mathrm{A}$ & p. (Thr55Asn) & Non-Synonymous & Polymorphism & tolerated $(0.24)$ & Benign (0.005) \\
\hline c. $166 \mathrm{G}>\mathrm{A}$ & p. (Glu56Lys) & Non-Synonymous & Polymorphism & tolerated $(0.28)$ & Benign (0) \\
\hline c. $215 \mathrm{C}>\mathrm{G}$ & p. (Pro72Arg) & Non-Synonymous & Polymorphism & tolerated $(0.12)$ & Benign (0.083) \\
\hline c. $233 \mathrm{C}>\mathrm{A}$ & p. (Ala78Glu) & Non-Synonymous & Polymorphism & tolerated $(0.91)$ & Benign (0) \\
\hline c. $236 \mathrm{C}>\mathrm{T}$ & p. (Ala79Val) & Non-Synonymous & Polymorphism & tolerated $(0.15)$ & Benign (0.042) \\
\hline c. $239 \mathrm{C}>\mathrm{T}$ & p. (Pro80Leu) & Non-Synonymous & Polymorphism & tolerated $(0.07)$ & Benign (0.014) \\
\hline c. $254 \mathrm{C}>\mathrm{A}$ & p. (Pro85His) & Non-Synonymous & Polymorphism & tolerated $(0.15)$ & Possible damage (0.7) \\
\hline c. $306 \mathrm{C}>\mathrm{A}$ & p. $($ Thr $102=)$ & Synonymous & Polymorphism & & \\
\hline c. $326 \mathrm{~T}>\mathrm{C}$ & p. (Phe109Ser) & Non-Synonymous & pathogen & Deleterious $(0.01)$ & Possible damage (1) \\
\hline
\end{tabular}

\subsection{Parameters of Genetic Variability}

After alignment and correction and then deletion of the sequences showing a very large difference from the sequenced gene (10 sequences from blood samples and 27 sequences from tumour tissue were obtained), each with a length of $220 \mathrm{bp}$.

The $220 \mathrm{bp}$ analyzed in the 27 patients with uterine fibroids contained 13 polymorphic sites and a total number of mutations equal to 14 in the myomatous tissues and only one polymorphic site in the controls. Analysis of the nature of the mutations indicates a transition/transversion ratio of 0.19 showing that transversions (80.2) outnumber transitions (19.8). Another parameter tested is the rate of synonymous (mutations not causing amino acid changes) and nonsynonymous (mutations causing amino acid changes) substitutions which indicates that non-synonymous substitutions (0.0071) are slightly higher than synonymous substitutions (0.0049).

Table 4. Parameters of genetic variability.

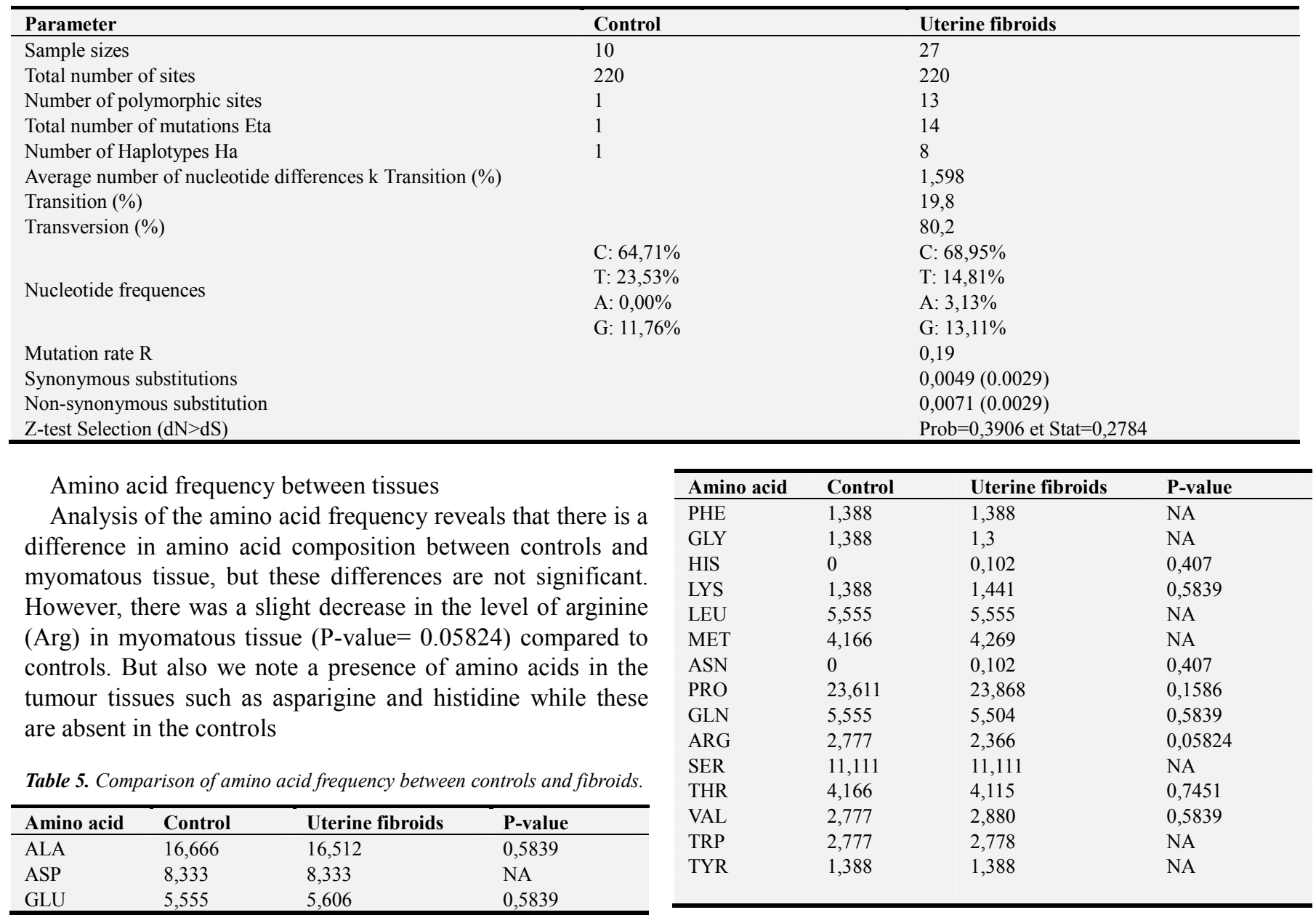




\subsection{Genetic Differentiation}

Analysis of intra-group and intergroup (control and uterine fibroids) genetic distances reveals that there is no difference between controls, whereas there is a difference in myomatous tissues. This analysis also indicated that controls and
Uterine myomas are genetically different $(D=0.0084$ and Fst $>0.5)$.

Similarly, the analysis of the genetic differentiation factor revealed a significant Fst ( $\mathrm{p}$-value $=0)$ indicating that the controls are genetically different from tumours tissues.

Table 6. Genetic differentiation.

\begin{tabular}{llll}
\hline & & Genetic distance of Nei & Factor of genetic differentiation (Fst) \\
\hline \multirow{2}{*}{ Intra-group } & Control & 0 & 0 \\
& Uterine fibroids & $0,0164(0.0042)$ & 0.53097 \\
Intergroup & Control & 0,0084 & $0,54258(\mathrm{p}$-value $=0)$ \\
\hline
\end{tabular}

\subsection{Correlation Between Polymorphism and Epidemiological Factor}

The genetic differentiation factor indicates a significant Fst for the group of women over 40 years of age

Table 7. Genetic structuring according to epidemiological parameters.

\begin{tabular}{lll}
\hline Clinical Parameters & GROUPS & FST BETWEEN SUBGROUPS \\
\hline & $\leq 30$ and $[30-40]$ & $0,42708(0,15315)$ \\
Age $(=18)$ & $\leq 30$ and $>40$ & $0,41176(0,05405)$ \\
& {$[30-40]$ and $>40$} & $0,20930(0,02703)$ \\
& 0 and 1 & $-0,34943(0,99099)$ \\
Gestity $(\mathrm{n}=13)$ & 0 and $[1-3]$ & $-0,34943(0,99099)$ \\
& 1 and $[1-3]$ & $1,00000(0,99099)$ \\
BMI $(\mathrm{kg} / \mathrm{m} 2)(\mathrm{n}=7)$ & $\leq 24$ and $[24-29]$ & $0,06383(0,27027)$ \\
& Wolof and Toucouleur & $0,07383(0,57658$ \\
Ethnicity $(\mathrm{n}=10)$ & Peulh and Wolof & $0,07383(0,60360)$ \\
Parity $(\mathrm{N}=13)$ & Toucouleur and Peulh & $0,20000(0,99099)$ \\
\hline
\end{tabular}

The analysis of genetic structuring shows a different evolution of the tumours depending on the epidemiological parameters. However, only the genetic differentiation factor of the age parameter is significant $(<0.05)$, which indicates that individuals of different ages present different tumours and that the group consisting of women aged between 30 and 40 years are more affected by this pathology.

Table 8. AMOVA test.

\begin{tabular}{llll}
\hline Clinical Parameters & Groups & Percentages of variation (\%) & Fst (P-value) \\
\hline \multirow{2}{*}{ Age $(\mathrm{n}=18)$} & $\leq 30$ & Intra 30,77 & $0,30769(0,00684)$ \\
& {$[30-40]$} & Inter 69,23 & \\
& $>40$ & Intra-39,01 & $0.39013(1.00000)$ \\
Gestity $(\mathrm{n}=13)$ & 0 & Inter 139,01 & \\
& 1 & & \\
$\mathrm{BMI}\left(\mathrm{kg} / \mathrm{m}^{2}\right)$ & {$[1-3]$} & Intra 6,38 & $0,06383(0,29521)$ \\
$(\mathrm{n}=7)$ & $\leq 24$ & Inter 93,62 & $0,16493(0,73216)$ \\
& {$[24-29]$} & Intra 16,49 & \\
Ethnicity $(\mathrm{n}=10)$ & Wolof & Inter 116,49 & \\
& Toucouleur & Intra-15,14 & $0,1514(0,90127)$ \\
\hline
\end{tabular}

The analysis of genetic diversity reveals a high haplopic diversity and a low nucleotide diversity for the three epidemiological parameters. However, these are much more significant in women aged between 30 and 40 years, with a body mass index (BMI) between 24 and $29 \mathrm{~kg} / \mathrm{m}^{2}$ and in women with only one child (parity $=1$ ).

\subsection{Evolution Test}

High haplotypic diversity and low nucleotide diversity were observed in myomatous tissues $(\mathrm{Hd}=0.778$; $\mathrm{Pi}=0.00921$ ).

Analysis of mismatch distribution curves for tissues with uterine fibroids under the assumption of a growing population gives a unimodal curve. The demographic indexes are positive (SSD and Rag) and non-significant, and the Tajima D-neutrality test, the $\mathrm{F}^{*}$ and $\mathrm{D}^{*}$ of $\mathrm{Fu}$ and $\mathrm{Li}$ tests produced negative and significant estimates. 


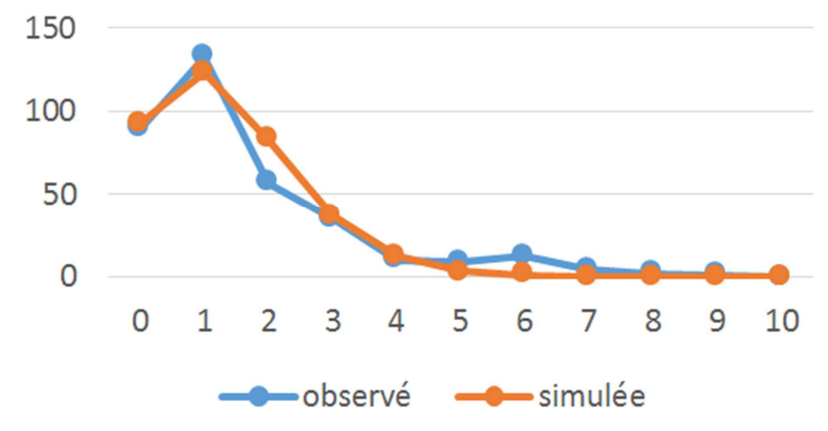

$\mathrm{SSD}=(0.00778 ; \mathrm{p}-\mathrm{value}=0.35)$ and $\mathrm{RAG}=(0.05885 ; \mathrm{p}-\mathrm{value}=0.56)$

Figure 2. Mismatch distribution curve under the hypothesis of a population in demographic expansion.

Table 9. Demographic indexes and neutrality test.

\begin{tabular}{lll}
\hline Indexes & Values & p-value \\
\hline Tajima's D & $-1,89018$ & 0,01 \\
Fs de Fu & $-2,38329$ & 0,09 \\
Fu and Li's D* & $-2,66909$ & $\mathrm{P}<0,05$ \\
Fu and Li's F* & $-2,88122$ & $\mathrm{P}<0,05$ \\
\hline
\end{tabular}

Table 10. Haplotypic (Hd) and nucleotide (Pi) diversities.

\begin{tabular}{ll}
\hline & Myomatous tissues \\
\hline Haplotypic Diversity Hd & 0,746 \\
Nucleotide Diversity Pi & 0,00726 \\
\hline
\end{tabular}

\section{Discussion}

This study aim is to identify mutations in the $p 53$ gene involved in uterine fibroids in Senegalese women, to determine the genetic diversity and evolution and the structuring of the gene according to epidemiological parameters (age, ethnicity, gestity, parity and BMI). Analysis of nucleotide variability made it possible to detect several mutations in the $p 53$ gene in fibrous tissues (19) and a single mutation (1) in controls (blood samples). This indicates that these variations could be involved in uterine fibroids in Senegalese patients. Of the twenty-seven (27) tumours tissues analyzed, nineteen (19) had a mutation in the $p 53$ gene and most of them are considered simple polymorphism by mutation prediction databases except for the c.326T $>C$ mutation (having a deleterious effect).

The heterozygous mutation c.326T $>C$ (p.Phe109Ser) leading to substitution of phenylalanine by serine at position 109 in protein TP53 is in a highly conserved domain (DNAspecific binding site), considered to be the hotspots of major mutations (residues 102 to 292). Indeed, following an alteration of the DNA binding site, protein TP53 loses its anti-oncogenic properties, so the cell continues to divide and accumulate mutations: this genomic instability would be at the origin of the increase in tumor aggressiveness. This c.326T $>C$ variant (rs1064796722) has also been identified by the studies of [11] in South Africa as probably pathogenic in two related patients (A and $\mathrm{B}$ ) with Li-Fraumeni syndrome (LFS). Indeed, the authors found that in addition to having Li-Fraumeni syndrome, patients A and B also had breast cancer and adrenal corticosurgery (cancer developed from the adrenal cortex), respectively. Li-Fraumeni Syndrome is a rare, autosomal dominant disorder that predisposes patients to various types of tumors at an early age. The presence of this pathogenic mutation could explain the severity of symptoms and the early age of onset of uterine fibroids in our patients ( 25 years old) compared to Caucasian women.

The c. $215 \mathrm{C}>\mathrm{G}$ mutation affecting codon 72 of exon 4 was found significantly (in 19/27 patients) in tumour tissue). This polymorphism at codon 72 of exon 4 of the p53 gene is the non-synonymous substitution of C (cytosine) by G (guanine) leading to a replacement of the amino acid proline $(\mathrm{P})$ by arginine (R). This polymorphism occurs in the proline-rich domain of the p53 gene which is necessary for the protein to fully induce apoptosis. It has been reported in the litterature associated with certain types of pathologies at a frequency of 0.457 (AlaMutvisual). Studies have shown that this rs1042522 $C>G$ polymorphism could promote tumour development but no consensus has been reached. Authors [12] and [13] showed that women carrying the Pro allele (Pro/Pro genotype) have a higher risk of uterine myomas than those carrying the Arg allele (Arg/Arg genotype) in Caucasian populations and equivalent proportions between controls and uterine myomas for the Pro/Arg genotype, similar with studies by [14] and [26] who found an association with endometriosis and cervical cancer respectively. This is in contradiction with our results: out of 27 patients recruited, 19 carry the Pro/Arg genotype (heterozygous mutation in the c. $215 \mathrm{C}>\mathrm{G}$ position of codon 72). [15], found an association between the Arg allele and an increased risk of cervical cancer in women infected in India with HPV 16/18 viruses contrary to those found by [6] and [25] respectively in Senegal and South Africa where no association was found. These differences can be explained by the fact that the R72 variant (arginine72), when found in mutant forms of $p 53$ as in our study, may promote tumor development (increased inactivation of p73), but when found in the context of wildtype $p 53$ may inhibit tumour development (increased apoptotic capacity) [16] but they can also be explained by the insufficient number of controls in our study.

For the first time c.215_216insG and c.274_275insG base insertions affecting codons 73 and 92 respectively have been found in uterine fibroids. These variants, also found in a proline-rich zone and involved in apoptosis processes, could also promote the resistance of tumour cells to control.

Our results also show for the first time a mutation in the control tissues (c.275C $>\mathrm{G}$ ) leading to a substitution of proline by arginine at codon 92 of exon 4 of $p 53$. This could play a protective role for non-tumor cells.

Among the variations found, $75 \%$ are substitutions and transversion type mutations $(80.2 \%)$ are the majority in uterine fibroids. The latter, which cause changes in the conformation of the protein structure, are all the more numerous at the level of the second position of the codon. This further confirms our hypothesis that the gene could play a role in the occurrence of this tumor. This is further supported by the analysis of the Z-test selection which indicates that the non-synonymous substitutions are slightly 
more numerous than the synonymous substitutions (Stat $>0$ ). This indicates that these changes could have consequences on the function of the protein: indeed p53 mutations confer a selective advantage to tumour cells by allowing them to avoid cell cycle control bridges, avoid apoptosis and proliferate under conditions where normal cells cannot.

Analysis of the amino acid composition showed the presence of amino acids such as asparagine and histidine in tumour tissues while these were absent in controls. Indeed the study of [17] have shown that asparagine (non-essential amino acid) is a glutamine-derived metabolite important for proliferating cells, and that maintenance at intracellular levels of asparagine is essential for the growth of cancer cells. Therefore the presence of this amino acid may be essential for tumour cell growth. It has also been shown that intracellular concentrations of asparagine regulate the absorption of amino acids, particularly serine, histidine and arginine. However, a decrease in the latter has been noted in tumour tissues. Indeed arginine, which is a semi-essential dibasic and cationic amino acid, has several immunomodulatory effects such as stimulating the activity of T-cells and natural killer cells [18]. Consequently, a decrease in this amino acid could allow tumor cells to escape the control of the immune cell defense system. This study also indicated that arginine is the only precursor to the nitric oxide (NO) molecule. The latter has a dichotomous (dosedependent) role in tumours, it may involve several mechanisms including direct damage to DNA and proteins or the inhibition of programmed cell death thus promoting abnormal cell growth [19] but it may also inhibit the proliferation of a cell line by positively regulating tumor suppression pathways including the BRCA1/ p53 pathway leading to cell cycle arrest [20].

A significant genetic differentiation factor $(F s t)(p<0.05)$ showed between control and myomatous tissues but also a genetic difference between uterine myomas $(\mathrm{d}=0.0164)$. The difference between myomatous tissues is thought to be responsible for the different location of the myomas in the uterus. Myomas come in extremely variable forms (subserous, intramural and submucosal myomas) and this variability is characterized by their size, consistency and different location in relation to the myometrium.

Analysis of the genetic structuring of uterine fibroids as a function of epidemiological parameters (Age of the patient, Gestity (number of pregnancies per woman), BMI, Ethnicity and Parity) shows that there is a genetic structuring of uterine myomas as a function of the age of the patient $(\mathrm{P}$-value $<0.05)$ in Senegalese women. In this study the average age for our patients is 38 years with extremes between 25 and 50 years. Women in the age range between $30-40$ years are the most affected $(55.55 \%)$. These results are in agreement with those found by [21] who showed that in Senegal the decade between 30 and 39 is the most affected $(51.29 \%)$ by uterine fibroids. Is the susceptibility of myomas related to the age factor? Two arguments can explain these results: the low reproductive rate of these women (parity less than or equal to 1) which constitutes an increased risk of uterine myomas or the increased exposure to estrogen. It is well known that uterine myomas are hormone-dependent tumours and that women in this age group are exposed to hormones. Study by [22] reported that the estrogen receptor alpha (ER $\alpha$ ) binds to the TP53 protein and suppresses its nuclear function in breast cancer cells, but also that disruption of this ER $\alpha-p 53$ interaction in vivo results in restoration of functional $p 53$ and a response of the cells to radiation therapy. Indeed, authors [23] have hypothesized that estrogen may partially stimulate the growth of leiomyomas by decreasing p53 protein levels in the nucleus and suppress its normal functions. Further studies are needed to see the role of this interaction ER $\alpha$-p53 in myometrial tumors cells.

A high haplotipic diversity $(\mathrm{Hd}=0.764)$ was obtained associated with a low nucleotide diversity $(\mathrm{Pi}=0.00726)$ suggesting a rapid multiplication of tumors cells. Indeed, the mutant $p 53$ functions as a cofactor capable of supporting the expression of several pro-oncogenic genes that affect several signaling pathways and whose aberrant activation contributes to an increased proliferation of tumor cells. Tumors cells with a mutation in the p53 gene are no longer able to maintain genetic integrity and therefore the cell no longer receives a signal to stop division and apoptosis. As a result, they can no longer be eliminated and continue to proliferate in an uncontrolled manner.

The neutrality indexes $\mathrm{D}^{*}$ and $\mathrm{F}^{*}$ of $\mathrm{Fu}$ and $\mathrm{Li}$ and the $\mathrm{D}$ of Tajima have produced estimates with negative and significant values which suggest an excess of rare variants or the effect of selective scanning. Of these two hypotheses the case of an excess of variants due to the elimination of deleterious mutations would confirm the non-lethal character of uterine myomas (benign tumors). Indeed p53 plays a role in the repair of DNA mismatches: following DNA damage, the protein rapidly accumulates and becomes activated. The gene binds strongly to strand breaks through its C-terminal domain, leading to stabilization and activation of the protein. This activation of the $p 53$ gene has two consequences: either cell growth arrest or apoptosis [24]. These results are further elucidated by the analysis of the "mismatch distribution" curve where the distribution of the number of differences between haplotypes taken two by two under the hypothesis of a growing population gives a unimodal curve with no difference between the observed and simulated values (Rag and SSD not significant).

\section{Conclusion}

In summary, our initial results showed a genetic difference between control and uterine myoma tissues but also a significant presence of the hetc. $215 \mathrm{C}>\mathrm{G}$ variant affecting codon 72 of the $p 53$ gene in myomatous tissues. They also showed for the first time a variant located in the specific binding domain to the probably damaging DNA (c.326T $>$ C) in tumours tissues: the identification of variants located in a highly conserved region of the DNA (exon 4) and specific to uterine myomas of the $p 53$ gene (a tumour suppressor gene involved in the processes of cellular apoptosis) would allow a 
better understanding of the etiology of uterine myomas. The epidemiological study showed a genetic structuring of uterine myomas according to the age of the patient and that the decade $30-40$ years was more affected by the tumor. Finally, our results also showed that the $p 53$ gene is not under positive selection but the mutations found in certain regions of this gene could constitute a susceptibility factor in women with uterine myomas.

\section{Acknowledgements}

The authors are most grateful to all Senegalese women who participated in the present study. We are extremely grateful to Dr Kénémé and Dr Tendeng who helped with the collection of samples. Also Pr SEMBENE the head of biology molecular platform of BIOPASS institute of Senegal for all the molecular studies done.

\section{References}

[1] Nourelhouda C., Abbassia D. (2013). Profil épidémiologique des fibromes utérins dans la région de Sidi Bel Abbes, Algérie. Pan African Medical Journal; 15 (7): 1-8.

[2] Rongières C. (1999). Épidémiologie du fibrome utérin: facteurs de risques et fréquence. Impact en Santé Publique C. J Gynecol Obstet Biol Reprod; 28: 701-706.

[3] Peddada S. D., Laughlin S.K., Miner K., Guyon J., Haneke K., Vahdat H. L., Semelka R.C., Kowalik A., Armao D., Davis B.,Baird D. D. (2008). Medical Science; 50 (105): 3-8.

[4] Dia A., Beye S.B., Dangou J. M., Dieng M., Woto Gaye G., Toure C.T. (2003). Les fibromes utérins à la clinique chirurgicale de Dakar: à propos de 140 cas opérés en deux ans. Dakar Médical; 48 (2): 72-76.

[5] Al-hendy A., Salama S.A. (2006). Ethnic distribution of estrogen receptor polymorphism is associated with a higher prevalence of uterine leiomyomas in black Americans. Fertility and Sterility; 3 (86): 686-693.

[6] Ndiaye R., Dem A., Mbaye PM., Guèye PM., Diop G., Diop P., Faye O. (2014).Étude du codon 72 du gène p53 dans la prédisposition au cancer du col de l'utérus au Sénégal. Bull Cancer; 101: 789-94.

[7] Hall T.A. (1999). BioEdit: a user-friendly biological sequence alignment editor and analysis program for Windows 95/98/NT. Nucl Acids Symp Ser. 41: 95-98.

[8] Tamura K., Stecher G., Peterson D., Filipsk Ai. Kumar S. (2013). MEGA7: Molecular Evolutionary Genetics Anslysis version 7. Mol Biol Evol; 30: 2725-2729.

[9] Rozas J. Librado P. (2009). DnaSP version 5: a sofware for comprehension analysis of DNA polymorphism data, Bioinformatics; 25: 1451-1452.

[10] Exoffer L., Laval G., Schneider S. (2010). Arlequin version 3.1: An integrated software packagefor population genetics data analysis. Evol Bioinform Online; 1: 45-50.

[11] Macaulay S., Goodyear Q C., Kruger M., Chen W., Essop F., Krause A. (2018). The first two confirmed sub-Saharan
Africain families with germline TP53 mutations causing LiFraumeni syndrome. Family Cancer; 4 (17): 607-613.

[12] Denschlag D, Bettendorf H, Watermann D, Keck C, Tempfer C., Pietrowski D. (2005). Polymorphism of the p53 tumor suppressor gene is associated with susceptibility to uterine leiomyoma. Fertility and Sterility; (84). 162-166.

[13] Yaghmaei M, Salimi S, Namazi L., Farajian-Mashhadi F. (2015). Association of XRCC1 Arg399Gln and Tp53 Arg72Pro polymorphisms and increased risk of uterine leiomyoma-A case-control study. Genetics and Molecular Biology; 4 (38): 444-449.

[14] Roh J, Kim J, Park N, Song Y, Kang S. Lee H. (2004). P53 and p21 genetic polymorphisms and susceptibility to endometrial cancer. (93): 499-505.

[15] Saranath D., Khan Z., Tandle AT., Dedhia P., Sharma B., Dinshaw K. (2002). HPVA16/18 Prevalence in Cervical Lesions /Cancers and P53 Genotypes in Cervical Cancer Patients from India. Genecologic Oncology; 2 (86): 157-162.

[16] Pietsch E C., Humbey O., Murphy M E. (2006). Polymorphisms in the $p 53$ pathway. Oncogene; 1602-1611.

[17] Krall AS., Xu S., Graeber T., Braas D., Heather R. (2016). Asparagine promotes cancer cell proliferation through use as an amino acid exchange factor. Nat Commun; 7.

[18] Lind DS. (2004). Arginine and Cancer. The Journal of Nutrition; 134 (10): 2835-2841.

[19] Cao Y., Feng Y., Zang Y., Zhu X. (2016). L-Arginine supplementation inhibits the growth of breast cancer by enhancing innate and adaptive immune responses mediated by suppression of MDSCs responses in vivo. BMC Cancer; 16 (343).

[20] Keshet R., Erez A. (2018). Arginine and the metabolic regulation of nitric oxide synthesis in cancer. Desease Models \& Mechanisms.

[21] Dièye M: Contribution à l'étude des fibromes utérins à propos de 154 observations recueillies à la clinique chirurgicale du CHU de Dakar. These Med., Dakar, 1883, numéro 130.

[22] Lui W., Margot M., Podgorsak B., Das G. (2009). Disruption of oestrogen receptor $\alpha-\mathrm{p} 53$ interaction in breast tumor: a novel mechanism underlying the anti-tumor effect of radiation therapy. Breast Cancer Res Treat; 115 (1): 43-50.

[23] Gao Z., Matsuo H., Nakago S., Kurachi O., Maruo T. (2002). P53 Tumor Supppressor Protein Content in Human Uterine Leiomyomas and Its Down-Regumlation by $17 \beta$-Estradiol. The Journal of Clinical Endocrinology \& Metabolism; 8 (87): 3915-3920.

[24] May P., May E. (1999). Twenty years of p53 research: structural and functional aspects of the p53 protein. Oncogene; 18: 7621-7636.

[25] Pegororo R., Moodly J., Naiker S., Lanning P., Rom L. (2000). The p53 codon 72 polymorphism in black South African women and the risk of cervical cancer. Obstetrics \& Gyneacology; 9 (107).

[26] Zhou X., Gu Yang., Zhang S. (2012). Association between p53 codon 72 polymorphism and cervical cancer risk among Asians: a HuGE review and meta-analysis. Asian Pacific journal of cancer prevention; 13 (10): 4909-4914. 